\title{
El impacto de los conjuntos de trilleros en el registro paleolítico de la Meseta. Una aproximación etnoarqueológica
}

\section{The influence of the 'threshing board' sites on the Meseta Palaeolithic record. An ethnoarchaeological approach}

\author{
David Álvarez Alonso*, María de Andrés Herrero** \\ Departamento de Prehistoria y Arqueología. C.A. UNED-Asturias \\ Avda. del Jardín Botánico 1345 (calle interior) - 33203 Gijón \\ *dalvarez@gijon.uned.es \\ **mariadandres@gmail.com
}

Recibido: 15-07-2010

Aceptado: 10-03-2011

\section{RESUMEN}

En el siguiente artículo se plantea la problemática que conlleva para el estudio del Paleolítico muchos depósitos líticos de carácter etnográfico y época histórica que se confunden con el registro arqueológico más antiguo. La principal aportación de este trabajo es la sistematización del proceso de elaboración de piedras de trillo en cuarcitas, y la caracterización geológica y arqueológica de estos conjuntos líticos en el territorio de Segovia.

Palabras Clave: Cuarcita. Paleolitico inferior. Talla lítica. Trillo. Cantalejo. Segovia.

\begin{abstract}
This paper analyzes the problem of the many archaeological assemblages found in the Castilian Meseta and created by the recent and contemporary activity of threshing cereals using wooden boards with stone tools ('trillero'), which can be misinterpreted as of Palaeolithic age. The process of threshing using quartzite stones is systematically described, as well as the knapping technology used to make the cutting tools and the geological and archaeological formation of the assemblages.
\end{abstract}

KEY WoRDs: Quartzite. Lower Palaeolithic. Lithic technology. Threshing board. Cantalejo. Segovia.

SUMARIO 1. Introducción. 2. Ámbito geográfico y geológico. 3. El trillo: origen y uso. 4. La fabricación de trillos en Cantalejo. 5. La elaboración de las piedras de trillo. 6. Los conjuntos líticos de trilleros y su análisis tecnológico. 7. El impacto de los conjuntos de trilleros en el registro arqueológico. 8. Conclusiones. 


\section{Introducción}

Con motivo de una prospección arqueológica ${ }^{1}$ encaminada a la catalogación de yacimientos paleolíticos, y llevada a cabo en la provincia de Segovia, fueron revisados una serie de conjuntos líticos que se encontraban inventariados en la Carta Arqueológica de la provincia, como yacimientos del Paleolítico inferior. Dichos conjuntos, realizados por completo en una cuarcita muy abundante en el entorno, se caracterizan por estar, en su práctica totalidad, formados por cantos trabajados y núcleos de cuarcita, documentándose también piezas de factura bifacial -según las descripciones que se habían dado en la Carta Arqueológica-. Estas descripciones fueron verificadas con la comprobación pertinente de campo y los posteriores hallazgos de conjuntos similares en otros puntos. Aunque en apariencia, los datos existentes en la Carta Arqueológica parecían apuntar a que nos encontrábamos ante yacimientos paleolíticos con una tecnología muy arcaica, y por lo tanto atribuibles a unos tiempos muy remotos (tal vez incluso preachelenses), la realidad resultó ser otra muy distinta.

Con el objetivo de realizar una verificación de estos hallazgos, se procedió a prospectar dichos yacimientos y a efectuar un estudio del entorno, para lo cual se comprobaron las áreas catalogadas, realizando una prospección intensiva y recogiendo muestras de material en todos los sitios. Tras efectuar un estudio de las piezas y de los conjuntos, desde un punto de vista tecnotipológico y geoarqueológico, en el cual se analizó el entorno sedimentario y las características geológicas de la zona, se pudo concluir que dichos conjuntos, no sólo no se encontraban asociados a contexto estratigráfico alguno, sino que tampoco existían contextos cuaternarios en el entorno de los que pudieran proceder dichos materiales. Por otra parte, los depósitos de los que provenían los cantos matrices, son niveles de edad cretácica, con abundantes y potentes estratos de arenas y cantos rodados, que incluso son objeto de explotaciones mineras en la zona.

En segundo lugar, el análisis efectuado a las piezas determinó que dichos elementos no se correspondían con ningún esquema tecnológico prehistórico, aunque en apariencia los resultados obtenidos fueran similares a determinadas piezas del Paleolítico, sobre todo del Paleolítico inferior. Por todo ello había que buscar una explicación a dichas acumulaciones, para lo cual fue necesario recurrir a la etnografía, analizando todo el proceso de elaboración de los trillos, una actividad sin duda muy importante en el medio rural y, como podemos apreciar, con un importante impacto arqueológico en la provincia de Segovia.

En este trabajo haremos referencia, en primer lugar, al ámbito geográfico y geológico en el que encuadramos las prospecciones realizadas. A continuación, repasaremos una breve historia sobre los orígenes, funciones y usos del trillo y su documentación en determinados contextos arqueológicos. Posteriormente, y con el objetivo de entender el proceso de formación de los conjuntos de trilleros, nos centraremos en el proceso de fabricación de trillos en Cantalejo (Segovia) para seguidamente poder analizar el impacto de la fabricación de estos aperos $\mathrm{y}$, más concretamente, de las piedras que contienen, en el registro arqueológico documentado en la provincia de Segovia. Por último, y para conseguir este objetivo analizaremos, desde un punto de vista tecnológico, los conjuntos de trilleros documentados en el término municipal de Pradales (Rodríguez de Tembleque 2007).

\section{2. Ámbito geográfico y geológico}

La zona de estudio se sitúa en el Noreste de la provincia de Segovia, al sur de la "Serrezuela de Pradales" - la cual alcanza su máxima altitud en Peñacuerno (1.377 m) - y entre las cuencas de los ríos Riaza y Duratón, afluentes del Duero (Figuras 1 y 2). La Serrezuela forma parte de una serie de bloques elevados, subparalelos al bloque principal (Sierra de Guadarrama), entre los que también están las elevaciones de Santa María La Real de Nieva y Sepúlveda (Cascos Maraña 1991; Díez Herrero y Martín Duque 2006; García Cortés et al. 1993).

Los conjuntos líticos estudiados se encuentran concentrados en una serie de elevaciones, caracterizadas por poseer un sustrato arenoso con abundancia de cantos rodados de cuarcita (y en menor medida cuarzo), que por otra parte resulta bastante frecuente en la zona. Dichos conjuntos se encuentran en posición primaria, principalmente en terrenos de cultivo y forestales, y en ocasiones se han documentado algunas piezas aisladas en otros terrenos adyacentes, situados en zonas de sustrato 
calcáreo y margo-arcilloso. Nuestro análisis se centra en cuatro conjuntos líticos situados en el término municipal de Pradales: Los Castillejos, La Solana, El Cerro de la Cabeza y Los Linares. Todos ellos figuraban en la Carta Arqueológica de Segovia como hallazgos y yacimientos del Paleolítico inferior (Fig. 3).

Los niveles de arenas y cantos de cuarcita, en los que se documentan los conjuntos, son muy frecuentes y están bien documentados en los distintos estudios geológicos efectuados en la zona. Se trata de la facies Utrillas del Cretácico inferior, que se prolonga hasta el Cenomaniense. Esta zona, destaca además por el denominado miembro "Arenas de Carabias", formado por gravas, conglomerados (compuestos por cantos de cuarcita bien redondeados y cuarzos), arcillas y arenas silíceas de tonalidades blancas amarillas y rosas, que alcanzan grandes espesores y que han sido, y siguen siendo, explotadas por actividades mineras. Tanto en Carabias como en Ciruelos (T.M. de Pradales) existen sendas explotaciones mineras a cielo abierto que se dedican a la extracción de estas arenas, y que nos permiten disponer de un corte estratigráfico visible para poder analizar el origen de estos depósitos de cantos de cuarcita.

Los únicos sedimentos cuaternarios en la zona son de origen fluvio-aluvial, y se sitúan en las zonas bajas de los valles, o al pie de las cuestas (en ocasiones formando terrazas de escasa envergadura). Por lo tanto, queda patente que de ninguna manera puede asociarse los contextos en los que se encuentran los conjuntos líticos con medios fluviales cuaternarios. No sólo eso, sino que en estos sitios el desarrollo edáfico es muy limitado, y por

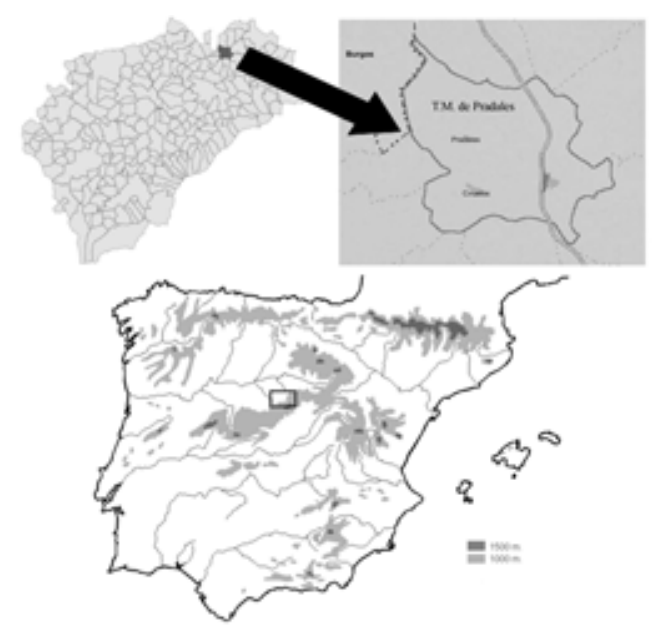

Figura 1.- Mapa de situación en la provincia de Segovia.

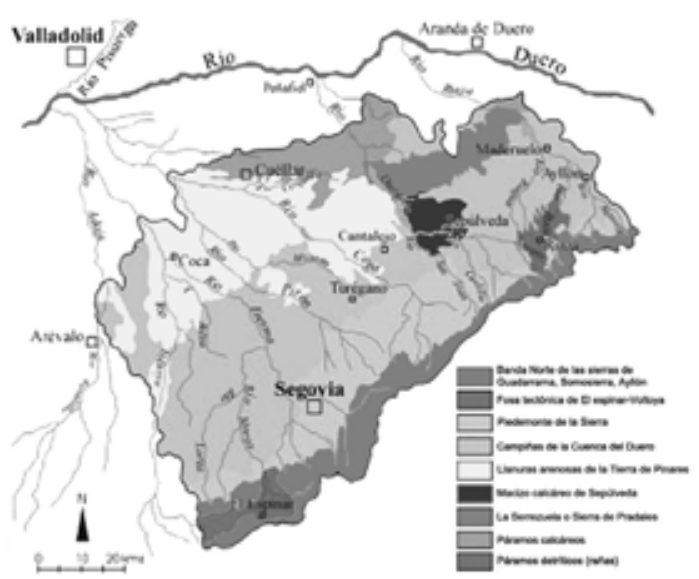

Figura 2.- Geomorfología de la provincia de Segovia (modificado de Tanarro 2006).
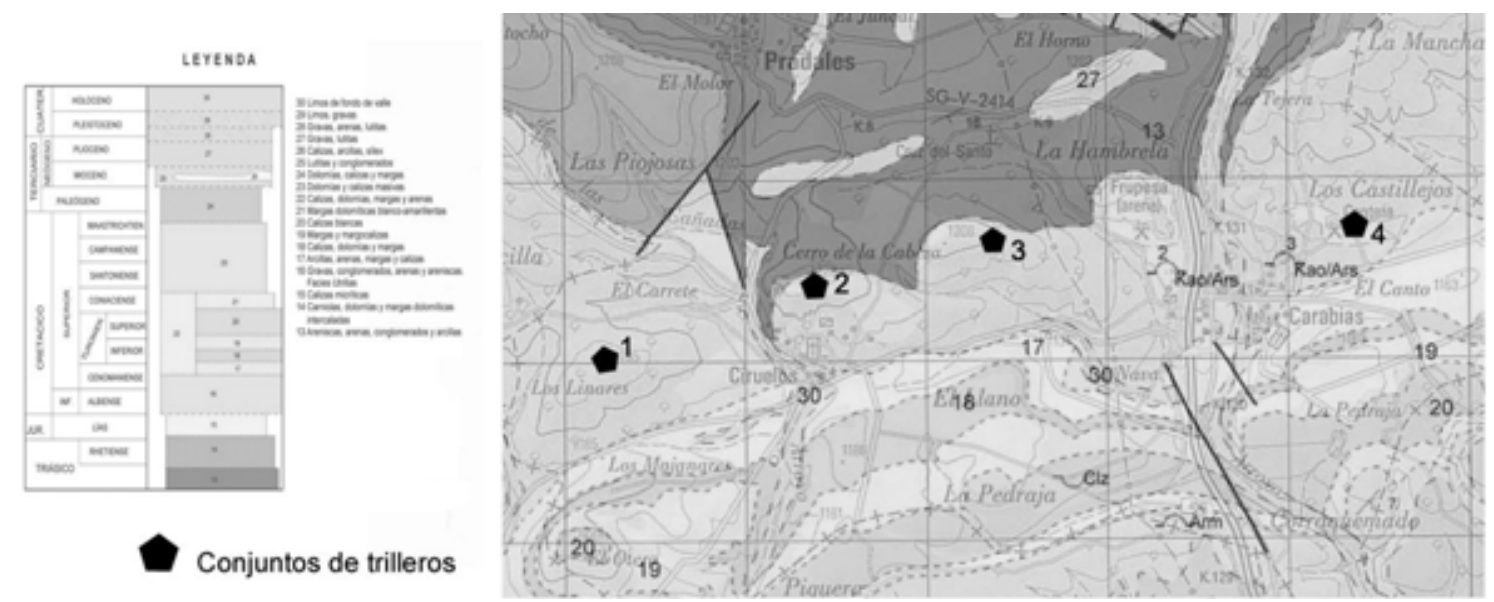

Figura 3.- Localización de los conjuntos líticos y marco geológico (modificado de IGME, 1993). 
lo tanto no se aprecia sedimentación cuaternaria de ningún tipo que haya podido generar suelos arqueológicos de cronología paleolítica.

Los depósitos de la facies Utrillas se disponen en sentido NE-SO y, a lo largo de su desarrollo, en aquellos puntos en los que afloran los potentes niveles de cantos (asociados a explotaciones mineras, barrancos, o simplemente zonas de erosión producto de la escorrentía) se ha concentrado la actividad de los trilleros, al disponer de abundante materia prima.

\section{El trillo: origen y uso}

La trilla es un proceso por el cual se produce la separación del grano de la paja o de cualquier resto vegetal, y que en nuestro ámbito de estudio está asociado principalmente con la recolección del trigo. En el área mediterránea la trilla se ha realizado desde los inicios de la producción agrícola en las eras.

Para el estudio de la Edad del Hierro, C. Cubero (1998) ha documentado arqueológicamente los tres métodos diferentes de trilla que ya fueron descritos por Plinio el Viejo (Chapa y Mayoral 2007):

$1^{\circ}$.- El batido, procedimiento propio de zonas húmedas y frías que consiste en el golpeo de las gavillas contra una superficie dura, como un muro o una piedra. Este método implica que la trilla se realiza en espacios cubiertos y para esta tarea en ocasiones se emplea un útil específico como el mayo o mayal, mediante una percusión indirecta.

$2^{\circ}$.- La frotación o pisoteado, técnica propia de zonas más cálidas en las que se procesan en un espacio abierto y de manera conjunta espigas y tallos justo después de la cosecha.

$3^{\circ}$.- La compresión, método que consiste en someter la parva al pisoteo del ganado (generalmente équidos o bóvidos) haciendo círculos.

Además de estás maneras de trillar, hay otra que emplea un apero llamado trillo. Estos instrumentos constan de varias tablas de maderas gruesas que poseen el frente un poco más estrecho y curvado hacia arriba, como si fuera un trineo. La estructura del trillo contiene lascas (generalmente de sílex) incrustadas en la madera, cuya parte cortante queda hacia el exterior de la misma para así poder arrastrarse correctamente sobre las mieses. Tradicionalmente el trillo ha sido arrastrado en movimientos circulares sobre la parva por bueyes o mulas.
Los trillos son unos instrumentos de una gran relevancia socioeconómica y, sin duda, marcaron un antes y un después en las labores agrícolas, facilitando la ardua tarea de la separación del grano de la paja.

Los primeros testimonios de restos de piedras de trillo documentados arqueológicamente se remontan al IV y III milenio a.C. En cuanto a la documentación escrita más antigua que hace referencia a estos aperos fue descubierta en Kish (Iraq), lugar donde apareció una plaqueta de arenisca datada a mediados del IV milenio a.C., grabada con una serie de pictogramas entre los cuales aparecen representados, entre otras cosas, trillos en sus dos caras que son bastante similares a los que hasta hace poco tiempo se empleaban en el Próximo Oriente. Asimismo, estos instrumentos aparecen descritos en algunas tablillas cuneiformes del III milenio a.C. También en el yacimiento turco de Arslantepe-Malatya se descubrió un cilindrosello que muestra un figura sentada sobre un trillo que ha sido datado en torno al 3400 a.C. y que algunos autores como Frangipane (1997) ponen en relación con la celebración de algún tipo de ritual, ya que además se asemeja bastante a otra escena pintada en los restos de las paredes de este yacimiento. Más recientes son unos textos cuneiformes del periodo sumerio que se remontan en torno al 1700 a.C., en los cuales se describen unos instrumentos que están formados por una serie de maderas atadas con tiras de cuero que conforman una estructura que aparenta una balsa en la que se colocan los dientes. Es importante señalar que los trillos eran unos aperos realizados por artesanos especialistas con piezas de sílex y obsidiana, resultando bastante caros, sobre todo en zonas como la Baja Mesopotamia, en la que era prácticamente imposible encontrar piedras. También se han excavado una serie de yacimientos como los localizados en Kutan, ciudad situada en el occidente de Irán y Tell Atij, urbe localizada al norte de Siria, donde se han documentado hojas de sílex con restos de brea que muy probablemente se hayan utilizado como dientes de trillo y que datan del Bronce inicial.

En Europa, el trillado del cereal ha sido documentado en yacimientos del Neolítico antiguo tan destacados como Nea Nikomedía (Van Zeist y Bottema 1971), Prodromos (Hallstead y Jones 1980) o Chevdar. Este último yacimiento fue excavado por R. Dennell (1976), quien observó que las 
muestras procedentes de suelos contenían un $1 \%$ mayor de semillas de malas hierbas, pero no de espiguillas, lo que le llevó a pensar que estaban en posición de preparación pero que ya habían sido trilladas y aventadas.

En el mundo clásico había divergencias en lo referente a la tecnología agrícola. Mientras que en Grecia la agricultura del cereal estaba poco desarrollada y el trillado, según la Ilíada, solía realizarse por pisoteo de bueyes, en el mundo romano el trillo está documentado por destacados autores como Catón, gran defensor de las costumbres ancestrales del mundo latino quien se oponía al uso de innovaciones exóticas como el trillo. Más tarde Varrón, en su tratado De Agricultura, habla del uso de este apero en la Hispania Citerior, mostrándose más abierto ante el uso del mismo que Catón. Según indica J. M. Blázquez (1983), los cartagineses fueron los introductores del trillo de rastro o trillo común, y del trillo de rodillos y cuchillas metálicas, en sus colonias peninsulares. Por su parte, y en relación a la difusión de los métodos de trillado en el caso concreto de la Península Ibérica, Herculano de Carvalho (1953) indica que las migraciones y la evolución socio-cultural de los grupos humanos son los dos aspectos fundamentales que han originado la difusión de los diferentes métodos de trillado ya que, en su opinión, los factores naturales, aunque importantes, quedarían relegados a un segundo plano.

Durante la Edad Media, en la Península Ibérica, y pese a que las referencias a estos aperos son escasas, existe documentación en la que se hace referencia a trillos que data de mediados del s. XIII, así como representaciones artísticas de estos aperos en relieves románicos como los de Campisábalos, en Guadalajara, y Beleña en Salamanca (Caro Baroja 1983).

Durante la Edad Moderna y Contemporánea el uso del trillo se generaliza en determinadas zonas de la Península. Por ello, podemos observar cómo este instrumento ha sido empleado hasta la introducción en España de la moderna maquinaria agrícola, en los años 60 del siglo pasado. Esto nos hace pensar en el número de restos líticos procedentes de esta actividad en época histórica, que pueden ser confundidos con restos prehistóricos, sobre todo paleolíticos.

\section{La fabricación de trillos en Cantalejo}

Los conjuntos líticos que analizamos en este trabajo, todos ellos situados en el noreste de la provincia de Segovia, se encuentran en el ámbito de influencia del foco de actividad trillera de Cantalejo. En la Meseta hay varias villas de tradición trillera, pero los artesanos que originaron las acumulaciones objeto de este estudio procedían, con probabilidad, de la villa segoviana, dado que se trata del centro artesanal más cercano. Es por ello, que en este punto repasamos la tradición y actividad realizada en Cantalejo en torno a la fabricación de los trillos, ya que no sólo nos ayuda a entender dicho proceso -acercándonos al modo de elaboración de trillos y "chinas"-, sino también nos sirve para contextualizar cronológicamente las acumulaciones líticas.

Los artesanos que realizaban los trillos en Cantalejo eran especialistas, más que en el trabajo de la madera, en la talla de las piedras. El oficio de estos briqueros ${ }^{2}$ generalmente pasaba de padres a hijos. Tenían edades comprendidas entre los 15 y los 70 años y podían ser miembros de una misma familia o trabajadores contratados esporádicamente, en cuyo caso tenían una jornada laboral de 10 horas (Siguero 1994).

La fabricación de los trillos en España durante la primera mitad del s. XX estaba centrada en una serie de poblaciones entre las que destacan Blesa y Albalate del Arzobispo, en Teruel; Ariza, en Zaragoza; Villavieja de Yeltes en Salamanca; Astudillo en Palencia; Cantalejo y Santa María la Real de Nieva en Segovia; o Pedrajas de San Estaban en Valladolid. Dentro de este oficio, entre los artesanos que más fama cobraron estuvieron los habitantes del pueblo segoviano de Cantalejo, los cuales hicieron de esta actividad su modo de vida principal, llegando a ser el trillo santo y seña de dicha población.

Pero los trilleros de Cantalejo no vivían sólo de la comercialización de los trillos y demás utensilios de labranza como arneros, bieldos, cedazos, horcas o cribas, sino que debían complementar su economía con la cría de ganado o el cultivo de productos agrícolas. Dicho trabajo está documentado en esta localidad al menos desde 1603, momento en el que aparecen trillos, cribas, taburetes, arcones, yugos y carretas reflejados en los protocolos notariales de esta localidad segoviana (Fuentenebro 1994). Esta industria trillera fue creciendo progre- 
sivamente, de tal forma que, a mediados del s. XX, Cantalejo contaba con más de 300 talleres en su término municipal, cada uno de los cuales solía fabricar unos 300 trillos anualmente, de ahí que se la conociera como la "Ciudad de los trillos". Esto significaba que la mitad de la población se dedicaba a la producción de trillos. Si además tenemos en cuenta que la mayoría de los trilleros pasaban más de cincuenta años de sus vidas dedicados a la fabricación de estos aperos (y por tanto, a la talla de las piedras que los componían), nos podemos ir haciendo una idea del importante registro arqueológico que han generado y del que quedan abundantes testimonios en los campos castellanos.

La importante actividad realizada por estos artesanos en Cantalejo tuvo consecuencias que van más allá de los aspectos socioeconómicos de los habitantes de esta población. Sin duda, lo más destacado es el patrimonio lingüístico legado por los briqueros: la gacería ${ }^{3}$, un idioma empleado como herramienta de trabajo indispensable por los trilleros y los tratantes de ganado en Cantalejo. Este idioma consiste en un código con el que los briqueros podían comunicarse con libertad en presencia de extraños, de modo que éstos no entendían el contenido de la conversación. Este argot, al igual que la industria trillera, vivió su momento de máximo esplendor con el auge que se produjo en el comercio de los trillos a principios y mediados del s. XX y su decadencia con la aparición de la maquinaria agrícola, a partir de los años 60 del siglo pasado. En 1960 quedaban más de 200 trilleros, en 1981 tan sólo 5 y en la actualidad la actividad trillera presenta pequeños resurgimientos meramente ornamentales. La desaparición de los trilleros provocó la reconversión económica de Cantalejo y supuso la emigración de algunos de sus habitantes.

En Cantalejo se fabricaban dos tipos de trillos diferentes: unos de piedra y otros de piedra y sierras. En cuanto al proceso de fabricación de los chiflos $^{4}$ podemos decir que éste comenzaba a finales del verano, con la tala de pinos negrales que se troceaban en tablones de entre $2 \mathrm{~m}$ y $2.5 \mathrm{~m}$. de longitud y de unos $5 \mathrm{~cm}$. de grosor con la parte superior de los mismos abombada (Siguero 1984). Posteriormente los listones de madera se secaban al sol apoyados en las casas durante varios meses, hecho que otorgaba una curiosa visión de Cantalejo. Una vez que dichos listones se habían secado se cruzaban unos con otros y se apilaban formando castillos. Tras comprobar que los listo- nes estaban en condiciones y no se habían alabeado, se escopleaban los listones al tresbolillo ${ }^{5}$ con un mazo de encina y tres escoplos de empuñadura cilíndrica denominados gordo, segundo y aguja, según el grosor de su cuchilla. A continuación, los listones se encolaban y prensaban y, una vez que estaban bien sujetos, se colocaban unos travesaños clavados en un primer momento con puntas y luego, a partir de 1700 , con unos clavos de hierro de cabeza redonda procedentes de Bilbao, denominados puntas de París. En ocasiones no se conseguía abastecer la gran demanda de clavos de los trilleros y, por ello, a veces empleaban clavos que tenían la cabeza en forma de trébol que se conseguían en el propio Cantalejo o en localidades próximas. De esta manera queda conformada la estructura básica del trillo. Lo único que faltaba para rematar el trabajo de dicha estructura era eliminar las irregularidades de la madera mediante el labrado y lijado de las tablas. Por último, se colocaban chapas en la parte frontal para tapar las uniones de los listones en la cara superior y se ponía un gancho en el cabezal delantero para poder ensartar un anillo de hierro con una correa o un largo palo que posibilitaba amarrar los animales de tiro.

Los trillos solían terminar de construirse en primavera y, por ello, en el mes de mayo familias de trilleros comenzaran a salir a vender los aperos hasta el mes de noviembre. En un primer momento realizaban el transporte de todo el material en carros, pero ya en las últimas etapas iban en camiones, con lo que la movilidad llegó a ser mayor. Las principales áreas donde los briqueros llevaban a cabo las ventas de sus productos en la segunda mitad del s. XX eran las dos Mesetas, algunos puntos de Cantabria, La Rioja, Aragón, Valencia, Extremadura y el Norte de Andalucía (Mingote 1990a, 1990b y 1995). Esta distribución de trillos por la Península no puede ser extrapolada de este momento del que estábamos hablando a la Edad Moderna, ya que el trillo no cumple una serie de requisitos que favorecen el comercio a larga distancia, como el hecho de que su fabricación puede llevarse a cabo en cualquier lugar y que la relación entre su peso y su volumen no compensaría su precio final, al que habría que sumar el transporte, además de impuestos de tránsito y venta. Por todo ello, autores como J. L. Mingote Calderón o Gómez Pascual $^{6}$ plantean la siguiente hipótesis: que la industria trillera de Cantalejo se desarrollase en paralelo al desarrollo de medios de transporte como

Complutum, 2011, Vol. 22 (1): 177-191 
el ferrocarril, que abarataría los costes del traslado de los trillos y demás aperos de labranza, con lo cual su gran desarrollo se produciría a finales del XIX y sobre todo, ya en el siglo XX.

A pesar de que esta industria trillera se desarrollara considerablemente desde finales del XIX, con motivo de su fácil exportación, en lo que respecta a nuestro territorio de estudio, próximo a Cantalejo, su transporte no sería complicado desde esta villa al menos desde principios del siglo XVII, que es cuando se empieza a documentar dicha actividad en Cantalejo. Pero no sólo eso, sino que estos artesanos debían trasladarse a las villas y pueblos cercanos a elaborar, e incluso reparar "in situ" estos trillos, dado el elevado volumen de cantos de trillero y focos de esta actividad reconocidos $\mathrm{y}$ dispersos por el noreste de la provincia de Segovia. De manera orientativa, podemos fijar un marco cronológico para la formación de estas acumulaciones de cantos tallados, en un periodo que iría como mucho desde el comienzo del siglo XVII hasta principios, e incluso mediados, del siglo XX.

\section{La elaboración de las piedras de trillo}

El material que usaban preferentemente los trilleros de Cantalejo era un sílex de color blanquecino que traían de pueblos de Guadalajara como Brihuega, Sacedón y Lupiana; y también de Cuenca, como Castejón. También empleaban sílex grisáceos, amarillentos y translúcidos. En las canteras de Jadraque y Sigüenza (Guadalajara) se extraían grandes bloques de sílex que posteriormente eran partidos con diferentes tipos de martilos hasta que conseguían un tamaño idóneo que permitiera a los briqueros asir con sus manos los núcleos de los que después extraerían las lascas (en gacería, chinas). Sin embargo, al ser la suya una labor ambulante, en ocasiones, cuando se les acababa el material, se veían obligados a enchiflar ${ }^{7}$ los trillos con lascas extraídas de cantos de cuarcita que recogían en zonas colindantes a los lugares donde vendían sus productos. Este dato resulta muy relevante para nuestro trabajo porque, tal y como veremos más adelante, la ausencia de sílex será la causante de la formación de los conjuntos de trilleros en esta zona.

La talla de la cuarcita que realizaban los trilleros es similar a la del sílex pero con una excepción, mientras que cuando tallaban sílex no aprovecha- ban el córtex y trabajaban este material hasta su agotamiento, en el caso de las cuarcitas los cantos eran "pelados y descartados", es decir, que únicamente aprovechaban las lascas corticales o, como son denominadas en gacería, las chinas costeras. Tal y como señalan Benito del Rey y Benito Álvarez (1994) los trilleros empleaban núcleos de cuarcita de grano fino para extraer, mediante un percutor duro (de hierro), unas lascas de aspecto y dimensiones muy estereotipadas. Estos autores realizan un estudio de las diferentes herramientas empleadas como percutores -generalmente martillos de hierro (Fig. 4)- partiendo de la necesidad de obtención de "chinas" de distintos tamaños en función de la posición que ocupan en el trillo. Hay que tener en cuenta que cada uno de estos aperos solía llevar unas 3000 piedras, colocadas según su tamaño: las pequeñas delante, las medianas en el centro y las más grandes en los laterales.

En cuanto a la talla para la obtención de chinas de sílex, según J. M. Barandiarán (Merino 1994), los picadores de piedra $^{8}$ trabajaban sobre lascas más que sobre riñones. Solían percutir los núcleos con martillos de acero para romper los núcleos y, una vez que éstos se fracturaban y tenían buenos planos de percusión, empleaban piquetas para extraer las lascas. J. M. Merino (1994) define a las chinas de trillo como ...pequeñas lascas de aspecto rectangular, más o menos regulares, poco espesas, a veces con restos de córtex, de sección triangular generalmente, y muchas con bulbos de percusión salientes y con estrellamientos, y ángulos de fractura obtusos. El talón suele ser poco marcado... además añade que nunca tienen retoques y que en ocasiones aparecen falsos retoques. Por otra parte señala que si fueron muy usadas, pueden pre-

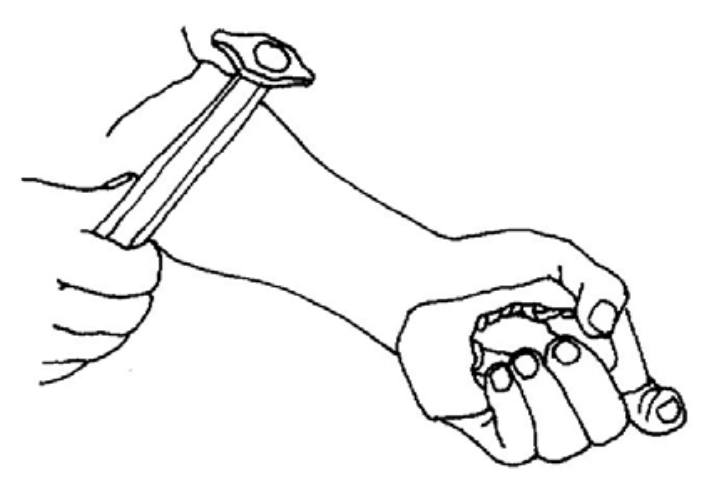

Figura 4.- Herramienta de trillero (Baena, J. 1998). 
sentar desgaste a lo largo de la mitad de la pieza. En cuanto a las dimensiones indica que oscilan entre 2 por 3 y 3 por $4 \mathrm{~cm}$.

Los picadores de piedra eran generalmente hombres. Éstos, solían protegerse la mano con la que agarraban la piedra que estaban tallando con una manopla de goma o badana. Mientras, con la otra mano sujetaban una piqueta con la que iban partiendo el sílex o la cuarcita, hasta que conseguían unos trozos con el grosor adecuado para los agujeros del trillo.

Mientras que la talla de las piedras solía ser una labor mayoritariamente masculina, la labor de enchiflado de los trillos solían realizarla las mujeres, quienes ajustaban las piedras a la parte posterior del trillo utilizando un martillo ${ }^{9}$, dejando el borde afilado de las lascas hacia el exterior y la zona más gruesa, o zona del talón de las lascas, ensartada en la ranura. Una vez que finalizaba la recolección de la cosecha, los trillos eran guardados en lugares secos y cerrados para evitar su deterioro.

\section{Los conjuntos líticos de trilleros y su análisis tecnológico}

Hemos procedido al análisis tecnológico de un conjunto compuesto por 120 piezas, a modo de muestreo, procediendo de los enclaves de $\mathrm{La}$ Solana, Cerro de la Cabeza, Los Linares y Los Castillejos, todos ellos pertenecientes al TM de Pradales (Segovia). En líneas generales todas las piezas siguen un patrón de talla similar (motivo por el cual se procedió a una selección en campo de 30 elementos por yacimiento) a la vista de lo observado "in situ" en cada uno de los lugares prospectados, en los que el material se presenta con características muy homogéneas y estereotipadas. En este apartado mostraremos cuáles son los morfotipos más habituales que nos encontramos en estos conjuntos de cantos tallados de cuarcita. Del mismo modo, también describiremos desde una perspectiva tecnológica, cómo se identifica este tipo de talla procedente de la actividad de los trilleros y en qué consiste.

El objetivo de la talla de cantos de cuarcita por parte de los trilleros es la obtención de lascas, generalmente corticales y de dimensiones más o menos regulares (suelen ser cortas y anchas). Es por ello que en cuanto se finaliza la fase de descortezado del canto, termina el aprovechamiento del mismo, siendo los residuos existentes en los yacimientos, en su práctica mayoría, núcleos sobre canto abandonados en fases incipientes de explotación, junto con alguna que otra lasca, generalmente de decorticado secundario o primario (con anversos que tienden a presentar extracciones unipolares o perpendiculares, y muy raramente centrípetas). Por esta razón, el análisis de la talla de cuarcita para la obtención de piedras de trillo debemos efectuarlo a partir de los núcleos y no de los productos, ya que estos últimos no son descriptivos, y los núcleos al no estar agotados, muestran perfectamente las secuencias de talla que pueden ser reconstruidas con gran facilidad.

Primeramente, podemos separar los núcleos de obtención de piedras de trillo a partir de cantos de cuarcita, en tres grupos.

1. Por un lado los que son afines a morfologías paleolíticas (Figs. 5-7).

2. Los que no presentan una morfología determinada (Fig. 8).

3. Los que presentan series aisladas (o no continuas, de extracciones), que evidencian un escaso aprovechamiento y que conservan mayoritariamente el aspecto original del canto (Fig. 9).

En el grupo 1 nos encontramos generalmente cantos afines a núcleos centrípetos (Figs. 6 y 7), a cantos trabajados e incluso a piezas bifaciales (Fig. 5) que pudieran ser confundidas con núcleos de explotación bifacial y en las más raras ocasiones con útiles bifaciales. Estas morfologías afines a tipos paleolíticos son el resultado del empleo de cantos planos y regulares, que evidentemente no suelen presentar más de dos planos naturales que son aprovechados, y como consecuencia de ello se van generando formas no intencionadas.

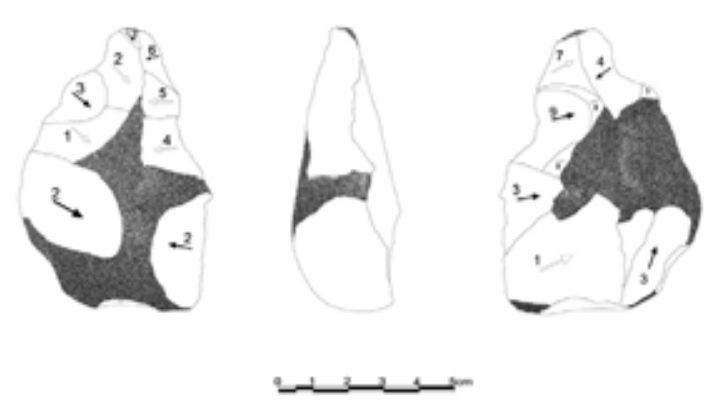

Figura 5.- Canto de trillero de morfología bifacial y afinidad paleolítica. 
En el grupo 2 tenemos una variedad amplia de morfologías que dependen en su mayoría del tamaño y número de caras que presentan los cantos (generalmente más de tres), en función de este aspecto se produce una talla multipolar, pero en ningún caso recurrente, que da como resultado cantos con numerosas extracciones pero sin ninguna afinidad tipológica al Paleolítico (Fig. 8). En estos núcleos se observa perfectamente el proceso de "pelado" realizado por los trilleros, que no conlleva distintas secuencias de talla, y se limita a agotar las superficies corticales del canto. En alguna ocasión alguno de estos núcleos puede presentar un esquema de talla afín al método Quina (Fig. 7), con plataformas de extracción y percusión secantes.

En el grupo 3 tenemos cantos de todos los tipos, la diferencia es la ausencia de secuencias amplias de extracciones, el escaso aprovechamiento del canto $\mathrm{y}$, en resumen, el bajo número de lascados que presentan, que evidentemente lo asemejan a un producto de testado (Fig. 9). Son sin duda los que menos problemas plantean, ya que pueden, incluso, parecer fortuitos.

Como se puede observar en las figuras (5-9) no existe una estrategia de talla definida ni predominante, primando la elección de los puntos de impacto sobre plataformas corticales, y en su defecto la alternancia bifacial, que es lo que acaba derivando muchas veces en la confusión de estos elementos con productos paleolíticos. Si bien estos grupos constituyen "grosso modo" los tres tipos en los que podemos encuadrar los cantos de manera genérica, al depender la talla de la morfología previa de los cantos, no es posible establecer una cuantificación real en cuanto a posibles preferencias en la elección de una estrategia tecnológica o morfología determinada. Los cantos se distribuyen entre los tres grupos de manera similar, lo cual nos indica la incidencia que tiene en este apartado la morfología previa. La existencia o predominancia de unos tipos u otros y su identificación, no debe ser un objetivo prioritario, ya que se nos antoja a la luz de las evidencias observadas, como algo aleatorio y totalmente secundario. Es por ello que la descripción general y la identificación de una pauta en la talla de estos productos sea mucho más primordial.

Igualmente, los yacimientos de trilleros se pueden dividir en dos grandes tipos en función de su ubicación geográfica y su contexto geológico: los que se encuentran en posición primaria y los que se encuentran en posición derivada o secundaria.

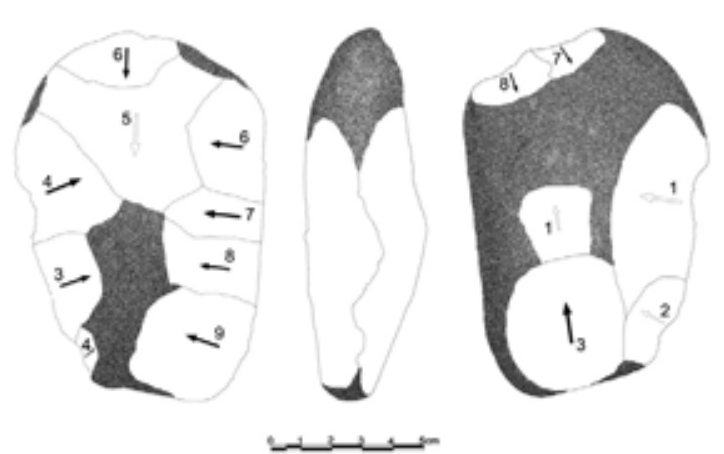

Figura 6.- Canto de trillero bifacial con talla de tipo centrípeto.

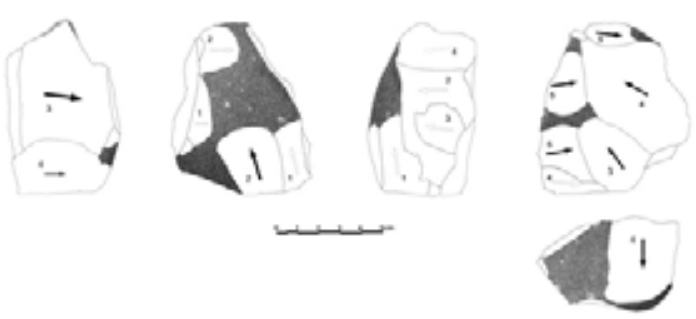

Figura 7.- Canto de trillero afín a núcleo paleolítico.
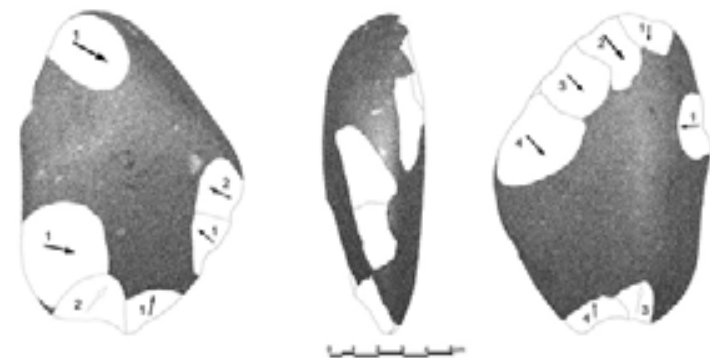

Figura 8.- Canto de trillero.

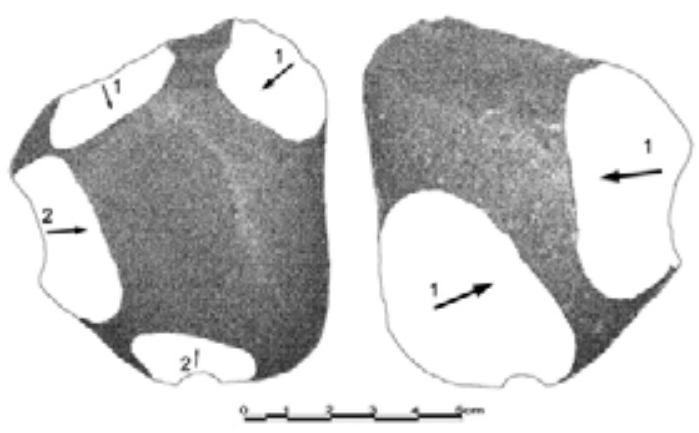

Figura 9.- Canto de trillero. 
Por lo que respecta a los primeros, los conjuntos de cantos tallados se hallan en los afloramientos de arenas y cantos rodados del Cretácico. Cuando estos depósitos geológicos se encuentran en lugares ligeramente elevados o en las cuestas de los distintos cerros que se encuentran en la zona -frecuentemente asociados a cárcavas o a zonas con una gran erosión fruto de actividad fluvial ocasional- es habitual encontrarse en esta parte de la provincia con estos yacimientos. Los Castillejos (Fig. 10) o La Solana (Fig. 11) sería un ejemplo de este tipo de enclaves.

Pero los hallazgos en contexto primario no sólo hacen referencia a los afloramientos, sino que también nos encontramos con zonas de cultivo situadas sobre dichos depósitos cretácicos o anejas a los mismos, en las que también se localizan talleres de trilleros debido al elevado número de materia prima existente. El Cerro de la Cabeza (Fig. 12) podría encuadrarse en este tipo de yacimientos.

En lo que se refiere a los yacimientos en posición secundaria, resulta habitual encontrar cantos de trilleros en muchos campos y eras, generalmente zonas de cultivo o en barbecho, en las que no existen los niveles geológicos que contienen cantos y arenas. En consecuencia, la posición de los cantos tallados de trilleros en estos contextos debe entenderse como su traslado a dichas zonas seguramente con el fin de reparar los trillos "in situ". Existen varios ejemplos de este tipo a lo largo del noreste de la provincia.
La cercanía a los núcleos de población no parece ser una circunstancia especialmente buscada por parte de los trilleros, ya que mientras Los Castillejos se encuentra cercano al núcleo de Carabias, y por su parte el pueblo de Ciruelos se encuentra al pie del Cerro de la Cabeza, lugares como La Solana se sitúan bastante alejados de los núcleos de población, eso sí, en todos los casos existen amplias masas boscosas que seguramente también fueron objeto de reclamo por parte de estos artesanos.

Debemos destacar, a partir de los datos etnográficos de que disponemos, que la formación de los conjuntos de trilleros se produciría durante los meses que éstos pasaban fuera de Cantalejo. En muchas ocasiones no iban únicamente a vender los aperos a las diferentes poblaciones, sino que además reparaban las posibles deficiencias que pudieran aparecer en los trillos, actividad que puede estar muy relacionada con la génesis del fenómeno de acumulación con el que nos encontramos.

Debido a su uso, los trillos iban perdiendo paulatinamente algunas de sus "chinas", por ello, los trilleros actuaban de dos maneras: en algunos casos acudían en busca de materias primas a zonas donde sabían que contaban con abundantes recursos cuarcíticos (como por ejemplo las torrenteras) en las que obtenían las chinas con las que posteriormente arreglaban los trillos. En otros casos las reparaciones se realizaban in situ, es decir en las mismas eras en las que se empleaban los trillos -en

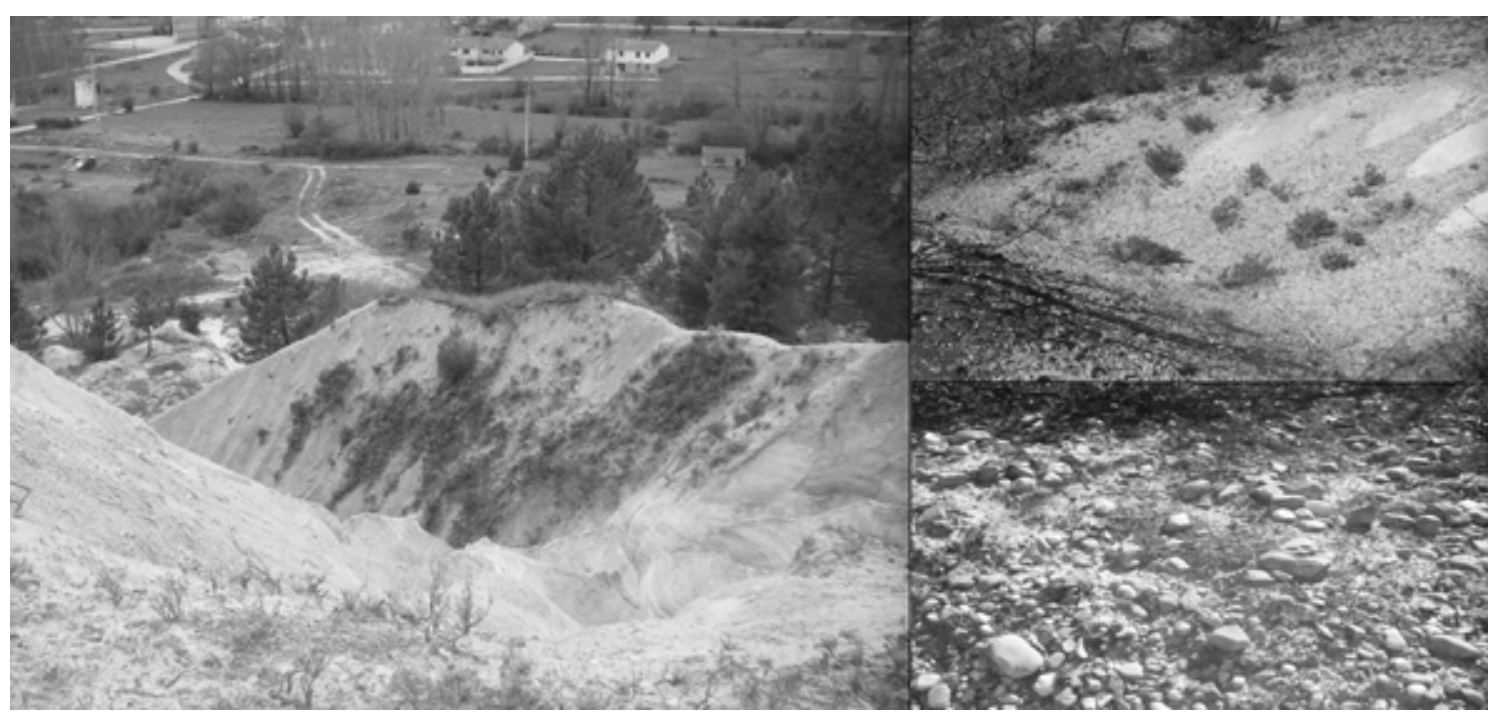

Figura 10.- Conjunto de Los Castillejos. Yacimiento en posición primaria, situado en un afloramiento elevado e independiente de las zonas de cultivo, pero cercano al pueblo de Carabias.

Complutum, 2011, Vol. 22 (1): 177-191 


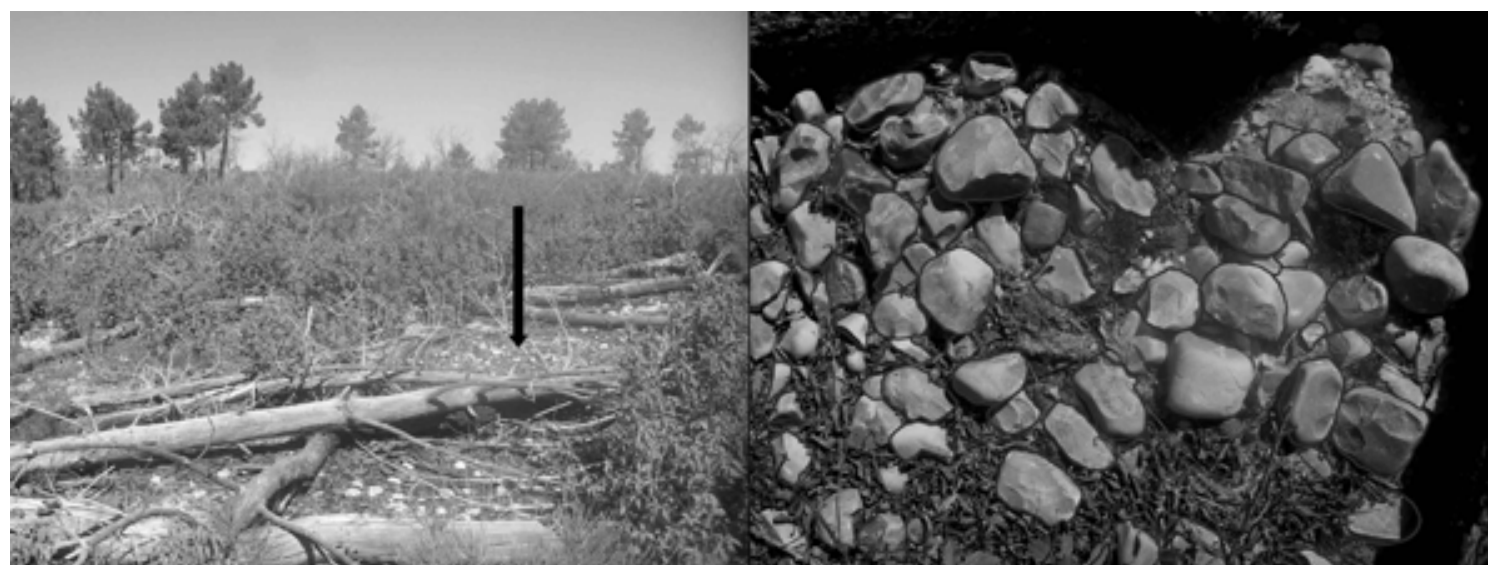

Figura 11.- Conjunto de La Solana. Yacimiento en posición primaria, alejado de núcleos de población y de zonas de cultivo. Este conjunto se localiza en un afloramiento cretácico, una zona elevada que actualmente se encuentra dedicada a pinar.

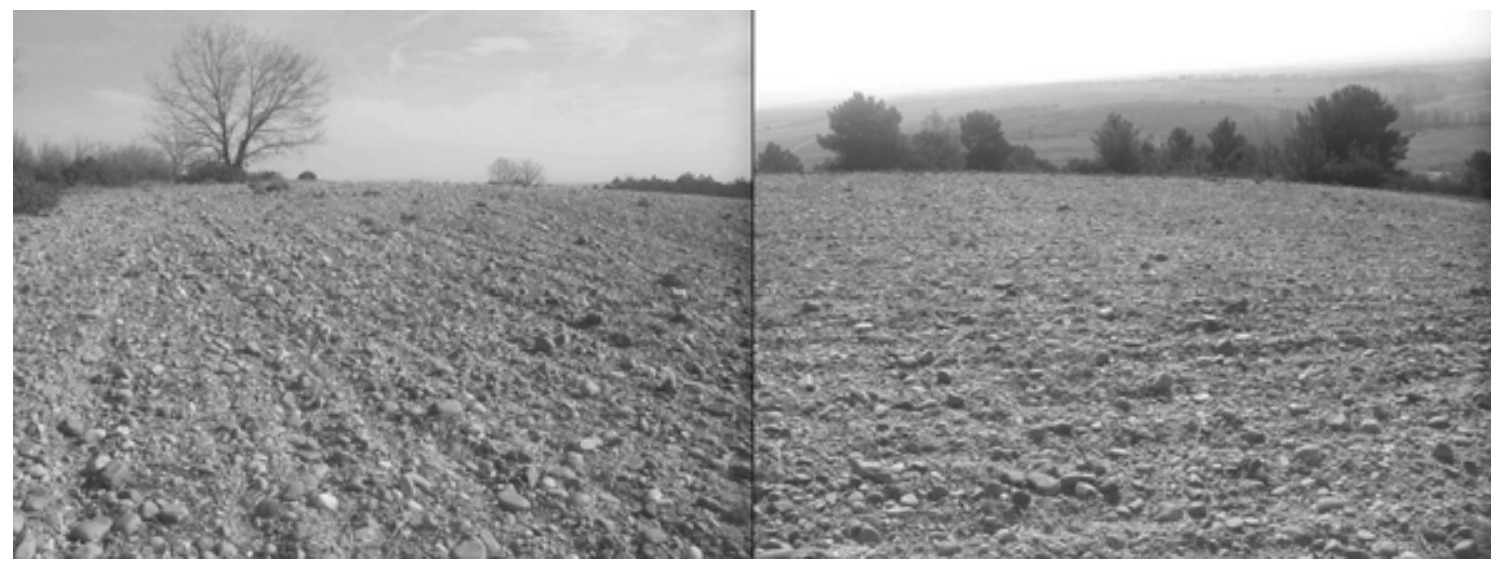

Figura 12.- Conjunto del Cerro de la Cabeza. Yacimiento en posición primaria. Se trata de una zona de cultivo situada sobre el sustrato cretácico, en el que afloran los cantos de cuarcita y las arenas de la "Facies Utrillas".

estas eras unas veces contaban con abundantes cantos de cuarcita, pero en otras ocasiones en el sustrato geológico están ausentes estos materiales-. Este dato resulta muy relevante porque es verificable en numerosos conjuntos de trilleros, como los documentados en el entorno de Pradales, en donde encontramos evidencias de la talla de cuarcitas que se encuentran en las propias eras y que suelen agruparse en pequeños conjuntos cercanos a árboles o zonas sombrías anejas a las mismas.

\section{El impacto de los conjuntos de trilleros en el registro arqueológico}

El impacto de esta actividad en el registro arqueológico puede ser similar al realizado por aficionados a la experimentación de la talla lítica prehistórica, aunque tal vez más fácilmente identificable. Mientras en el caso de la experimentación el objetivo es la reproducción de piezas y esquemas operativos paleolíticos, en este caso en el que nos centramos, se trata de tecnologías muy simples en las que claramente no existe la búsqueda de filo ni el retoque, primando por encima de todo la extracción de pequeñas lascas, generalmente de decorticado primario. Los conjuntos de trilleros, además, carecen de las pátinas y alteraciones postdeposicionales que los conjuntos paleolíticos, ya sean procedentes de depósitos de alta o baja energía, poseen en mayor o menor grado.

El hallazgo de este tipo de materiales y la dificultad, en muchas ocasiones (si no se está familia- 
rizado con las industrias paleolíticas y existe un desconocimiento de la importancia de la actividad de fabricación de los trillos, así como de sus productos), puede llevar a la confusión y la errónea documentación de yacimientos paleolíticos, por lo que es posible obtener mapas de dispersión de materiales prehistóricos alterados o erróneos ${ }^{10}$.

Podemos establecer una serie de características generales que identifican los talleres líticos de cuarcitas, fruto de la actividad de elaboración de piedras de trillo, y que los diferencian de los conjuntos paleolíticos:

$1^{\circ}$.- Ausencia de pátina y otras alteraciones postdeposicionales frecuentes en las industrias del Paleolítico inferior y medio al aire libre (rodamiento, alteraciones eólicas, levantamientos térmicos, etc...).

$2^{\mathrm{o}}$.- Ausencia de elementos retocados y útiles sobre lasca en los conjuntos.

$3^{\circ}$.- Muy bajo porcentaje de lascas sin córtex y presencia mayoritaria de lascas simples de decorticado primario o secundario.

$4^{\circ}$.- El punto de impacto que conserva cada negativo en ocasiones puede mostrar alguna marca ferruginosa, y en todos los casos se aprecia que se trata de una extracción reciente y provocada por un solo golpe, dejando además una concavidad muy marcada en el negativo resultante al plano de percusión.

$5^{\circ}$.- Presencia mayoritaria de elementos sobre canto (con aspecto de cantos trabajados y núcleos).

$6^{\circ}$.- Entre los elementos masivos, ausencia de filos retocados o configurados, así como de preparación de plataformas de percusión.

$7^{\circ}$.- Esquemas tecnológicos simples, utilizando tanto planos naturales corticales como planos de percusión, o planos de lascado, fruto de la alternancia bifacial.

8.- Escaso aprovechamiento de las materias primas y ausencia de recurrencia en la talla.

9.- Los cantos no tienden a presentar más de una secuencia de talla en cada plano (en los casos de mayor explotación), dejando de extraer lascas en el momento en que se agotan las superficies corticales. Como consecuencia, los cantos presentan el aspecto de haber sido pelados.

10.- Las lascas obtenidas son de pequeño tamaño, mayoritariamente inferiores a $\operatorname{los} 4 \mathrm{~cm}$ de longitud máxima.

A las características enumeradas, habría que añadir su localización geográfica. Muchos de los conjuntos de trilleros, tal y como se señaló al principio de este trabajo, se hallan en pequeños cerros en los que hay abundantes cantos de cuarcita, en terrenos de cultivo y en zonas forestales (Fig. 10, 11 y 12). En varias ocasiones se han identificado algunos conjuntos dispuestos alrededor de algún árbol, lo que nos está indicando claramente la realización de una actividad al amparo de la sombra, lo cual sin lugar a dudas ya nos está dando una pauta de actuación muy moderna, dado que muchos de estos árboles son ejemplares con menos de 100 años (frecuentemente pinos, robles o encinas). Esto puede deberse, tal y como se ha señalado anteriormente, a que el momento en el que los trilleros se desplazaban para realizar la venta de sus aperos y con el fin de efectuar las reparaciones de los trillos era entre los meses de mayo y noviembre. De ahí que estos artesanos buscasen cobijo del arduo sol de la Meseta en época estival, bajo los árboles. Llama la atención que, varios de estos conjuntos que se localizan bajo los únicos árboles que existen en algunos terrenos de labor, son más pequeños que otros, como los localizados en torrenteras (Fig. 13). Esto es probable que se deba a que los primeros son fruto de la reparación in situ de los trillos, mientras que los segundos, seguramente, sean lugares de captación de materias primas, en los que se aprovecha la elevada concentración de material cuarcítico para tallar, y en el mismo lugar desechar las "chinas" que no valían.

Consideramos todas estas características citadas como propias de los conjuntos líticos de trilleros elaborados a partir de cantos de cuarcita que es, como ya hemos comentado, la materia prima a la que recurrían estos artesanos cuando se desplazaban fuera de sus talleres, y ya no podían disponer de los sílex habituales que solían emplear.

\section{Conclusiones}

Tras este trabajo, creemos que no sólo queda reflejada una realidad existente en la Arqueología que se realiza en la Meseta, sino también se establecen las pautas que pueden servir a futuros trabajos a la hora de distinguir estos conjuntos etnográficos de hallazgos paleolíticos. El impacto que tienen los conjuntos de trilleros en el registro paleolítico se ve agravado, por una parte, cuando las prospecciones realizadas, así como el estudio de los 


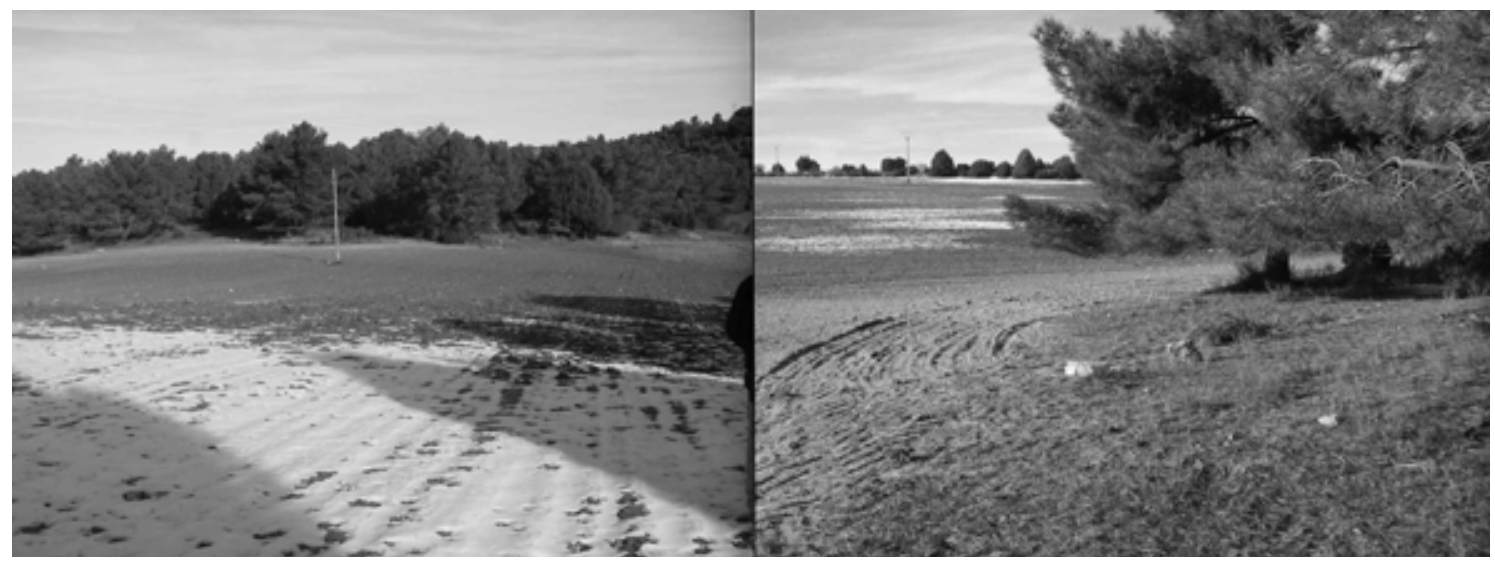

Figura 13.- Conjunto de El Estepar (T.M. de Villaverde de Montejo, Segovia). Ejemplo de yacimiento en posición secundaria y de localización de talleres en zonas sombrías. En la zona cultivada se hallan materiales de trilleros en posición derivada. Al fondo, en el pinar se ha localizado un taller de trillero, al amparo de los árboles y a expensas de un pequeño afloramiento cretácico.

materiales, son efectuados por arqueólogos ajenos a la investigación de los periodos paleolíticos. Por otro lado, efectuar una buena y completa documentación, tanto previa como en el posterior cotejo de la información recabada, es una circunstancia que no siempre se realiza con la intensidad necesaria.

La necesidad de incorporar el análisis geoarqueológico (Butzer 2007) a las investigaciones de campo creemos que es algo sumamente aconsejable, ya que el contexto en el que se documentan los hallazgos procedentes de las prospecciones es, a veces, la única información válida disponible.

Como resultado podemos encontrarnos con la intrusión (en varias ocasiones) en las Cartas Arqueológicas de realidades desvirtuadas, como es el caso que hemos presentado que pasan a engrosar, ficticiamente, el registro de yacimientos de un periodo determinado. Esta circunstancia es doblemente problemática, tanto para la investigación como para la Administración a la hora de plantear o valorar futuras actuaciones en el terreno.

Al margen del impacto que tienen los conjuntos de trilleros en el registro paleolítico, creemos que es importante documentar una actividad, que aunque sobradamente conocida, realmente es poco valorada, tanto en el impacto arqueológico como en la importancia económica que debió de tener, a la luz de los restos que jalonan el territorio.

Estos conjuntos, elaborados a partir de cantos rodados de cuarcita, pueden confundirse en un primer momento con restos paleolíticos, pero a la hora de efectuar un análisis de dichos materiales, y por supuesto, del entorno geológico y del contexto estratigráfico (del cual carecen), no ofrecen lugar a dudas. No presentan ninguna analogía con los métodos de talla del paleolítico, ni por supuesto con los productos resultantes de éstos.

Resulta obvio que muchos de estos conjuntos son producto de la actividad de trilleros, la cuestión es que en el desarrollo de la práctica arqueológica nos encontramos con estas problemáticas y no tenemos datos ni evidencias que nos permitan asegurarlo al cien por cien. Es por ello que este tratamiento que hemos dado a los conjuntos líticos de trilleros y a la talla lítica en época moderna y contemporánea, se hacía necesario.

\section{Notas}

1. Estas prospecciones están enmarcadas en el proyecto "Estudio geoarqueológico de la cuenca media de los ríos Duratón y Riaza (Segovia). El Paleolítico Inferior y Medio" autorizado por la Junta de Castilla y León, y que se está desarrollando desde el año 2008.

2. Briquero o trillero es el nombre con el que se conoce a los fabricantes y comerciantes de trillos, cribas y otros aperos de labranza. 
3. Los orígenes de este argot fueron estudiados por Sigfredo Arranz, quien indica que la gacería fue introducida por algunas familias procedentes de barrios bajos de Burdeos, así como por los monjes templarios franceses, que habían levantado una ermita en los alrededores de Cantalejo. Parece ser que estos gitanos de Burdeos hablarían esta jerga en el intento de ocultar conversaciones entre ellos en su tentativa de engañar a la hora de realizar un acuerdo económico. 4. En gacería, trillos.

5. Escoplear al tresbolillo consiste en realizar unas ranuras en la parte posterior del trillo, en las que después se insertarían las lascas de sílex o cuarcita.

6. Gómez Pascual señala que en el año 1946 una gran parte de los habitantes de Cantalejo se dedicaban al ganado mular.

7. Enchiflar es el verbo con el que se conoce, en gacería, a la acción de ensartar las piedras en el trillo.

8. Picadores de piedra es el nombre con el que se conoce a quienes se dedicaban a tallar las piedras para los trillos.

9. Este martillo era diferente de otros que empleaban los briqueros: es un utensilio de cabeza cilíndrica y extremos planos ya que el objetivo era intentar no dañar el filo de las piedras. Generalmente las piedras de trillo presentan pseudorretoques producidos por este martillo ligero.

10. En la Carta Arqueológica de la provincia de Segovia hemos detectado varios "hallazgos del Paleolítico inferior" que en realidad se corresponden con conjuntos de trilleros. Del mismo modo en el Museo Arqueológico Provincial de Segovia se encuentran depositadas algunas de estas piezas procedentes de prospecciones y como parte del corpus de material paleolítico.

\section{Agradecimientos}

Agradecemos el apoyo e interés de Jorge Santiago Pardo, arqueólogo territorial de la Junta de Castilla y León, en las investigaciones que se están desarrollando sobre el Paleolítico de la provincia de Segovia. Por otra parte también hemos de mostrar nuestra gratitud a Julio Rojo, parte integrante del equipo de investigación, por su colaboración en el trabajo de campo.

\section{REFERENCIAS BIBLIOGRÁFICAS}

ANDERSON, P.C. (1999): The history of harvesting and threshing techniques for cereals in the prehistoric Near East. The Origins of agriculture and crop domestication (A. B. Damania, G. Willcox y C. O. Qualset, eds.), ICARDA, IPIGRI, GRCP, FAO, Alepo.

Anderson, P.C., Cumings, L.S., Schippers, T.K., SimOnel, B. (eds.) (2003): Le traitement des récoltes: un regard sur la diversité, du Néolithique au présent. XXIII rencontres internationales d'archéologie et d'histoire d'Antibes, Éditions APDCA, Antibes.

Anderson, P.C.; Chabot, J.; Van Gijn, A. (2004): The Functional Riddle of "Glossy" Canaanean blades and the Near Eastern Threshing Sledge. Journal of Mediterranean Archaeology, 17: 87-130.

Ataman, K. (1992): Threshing sledges and archaeology. Préhistoire de l'agriculture: nouvelles approches expérimentales et ethnographiques, Monographies du RCA : 305-319.

Benito del Rey, L.; Benito Álvarez, J.M. (1994): La taille actuelle de la pierre à la manière préhistorique. L'exemple des pierres pour Tribula à Cantalejo (Segovia, Espagne). Bulletin de la Société Préhistorique Française, 91(3) : 214-224.

Blázquez, J.M. (1983): Historia de España Antigua. Tomo 1. Prehistoria. Ediciones Cátedra, Madrid.

Butzer, K. W. (2007): Arqueología, una ecología del hombre. Bellaterra, Barcelona.

Caro Baroja, J. (1983): Tecnología popular española. Editora Nacional, Colección Artes del tiempo y del espacio, Madrid.

Cascos Maraña, C.S. (1991): La Serrezuela de Pradales. Estudio geomorfológico. Ed. Universidad de Valladolid, Valladolid.

CASTIÑEIRAs GonZÁlez, M.A. (1993): Algunas peculiaridades iconográficas del calendario medieval hispano: las escenas de trilla y labranza. Archivo Español de Arte, 261: 305-319.

Chapa Brunet, T.; Mayoral Herrera, V. (2007): Arqueología del trabajo. El ciclo de la vida en un poblado ibérico. Akal, Madrid. 
Cuesta Polo, M. (ed.) (1993): Glosario de Gacería. Ayuntamiento de Cantalejo, Segovia.

Cubero, C. (1998): La agricultura durante la Edad del Hierro en Cataluña a partir del estudio de las semillas y los frutos. Seminari d'Estudis y Recerques Prehistòriques, Universidad de Barcelona, Barcelona.

DENNELl, R. (1976): The economic importance of plant resources represented on archaeological sites. Journal of Archaeological Science, 3: 229-247.

Díez Herrero, A.; Martín Duque, J.F. (2006): Las raíces del paisaje. Condicionantes geológicos del territorio de Segovia. Junta de Castilla y León.

FrangiPANE, M.A. (1997): 4th millennium temple palace complex at Arslantepe-Malatya. North-South relations and the formation of early state societies in the northern regions of greater Mesopotamia. Paleorient, 23(1): $45-73$.

Fuentenebro Zamarro, F. (1994): Cantalejo. Los briqueros y su gacería. Ayuntamiento de Cantalejo, Madrid.

García-Cortés, A.; Mansilla, H.; Quintero, I.; Torres, T.; Rubio Pascual, F. (1993): Maderuelo. Mapa Geológico de España, IGME, Madrid.

HalsteAd, P.; JonEs, G. (1980): Early Neolithic economy in Thessaly. Some evidence from excavations at Prodronos. Anthropologika, 1: 93-117.

Herculano de CARvalho, J.G. (1953): Coisas e palavras. Alguns problemas etnográficos relacionados com primitivos sistemas de debulha na Península Ibérica. Biblos, 29: 1-365.

Igme (1993): Maderuelo, 403. Mapa Geológico de España. Escala 1/50.000.

Merino, J.M. (1994): Tipología lítica. Suplementos de Munibe, San Sebastián.

Mingote Calderón, J.L. (1988): Mayales y trillos en España. Anales del Museo del Pueblo Español, 2: 83-167.

Mingote Calderón, J.L. (1990a): Catálogo de aperos agrícolas del Museo del Pueblo Español. Ministerio de Agricultura, Pesca y Alimentación, Madrid.

Mingote Calderón, J.L. (1990b): Mayales y trillos en la Provincia de León. Diputación Provincial de León, León.

Mingote CAlderón, J.L. (1995): No todo es trabajo. Técnicas agrícolas tradicionales. Centro de Cultura Tradicional, Diputación de Salamanca, Salamanca.

Rodríguez de Tembleque, J.M. (2006): Primeras ocupaciones humanas en la Meseta española: Estudio geoarqueológico de depósitos fluviales en la cuenca media del Tajo. Tesis Doctoral. Universidad Autónoma de Madrid

Siguero, A. (1984): Los trilleros. Revista de Folklore, 41: 175-180.

TANARRO, L.M. (2006): Geomorfología de los valles del piedemonte norte del Sistema Central en su sector segoviano: cuenca del río Duratón. Tesis Doctoral, Universidad Complutense de Madrid, Madrid.

Van Zeist, W.; Bottema, S. (1971): Plant husbandry in early Neolithic Nea Nikomedeia, Greece. Acta Botanica Nederlandia, 20 - 5: 524-538.

WhitTAKeR, J.C. (1999): Alonia: the ethnoarchaeology of Cypriot threshing floors. Journal of Mediterranean Archaeology, 12: 7-25. 